\title{
Perceptions of Students: Blended Learning for IR4.0
}

\author{
Jowati Juhary
}

\begin{abstract}
Industrial Revolution 4.0 (IR4.0) is the current key term today that affects various facets of humans' life. As society struggles to grasp its impact, academics are responsible to prepare the future workers, who must be able to cope with IR4.0 and beyond. This paper attempts to gauge students' perceptions of blended learning. At the same time, the author wants to investigate whether they perceive blended learning as a platform to help them face IR4.0 after graduation. A class taught by the author was observed for two semesters, and at the end of the second semester, all students in the class were asked five main questions on blended learning and their readiness to face IR4.0. Preliminary findings suggest that, firstly, students were not exactly comfortable learning in a blended learning environment and with flipped classroom as one of its strategies. Secondly, the majority of the respondents were unsure of what IR4.0 is, and yet they were confident that they would be able to face IR4.0. The author argues that much is still needed to be done in order to embrace IR4.0, despite the abundance of preparation to face it at various levels.
\end{abstract}

Index Terms-Blended learning, flipped classroom, industrial revolution 4.0, teaching and learning.

\section{INTRODUCTION}

Industrial Revolution 4.0 (IR4.0) is the current 'buzzword' that has changed many aspects of humans' life. The most affected, arguably, is the education sector, where academics are pressured to prepare future workforce of a nation. This paper investigates students' perceptions of blended learning. Further, the author wants to examine whether they perceive blended learning as a platform to help them face IR4.0 after graduation.

The methodology adopted in this paper was a mixed method approach; an observation and a set of checklist were used to observe the same group of students for two semesters, and an online survey was distributed for them to answer at the end of the second semester. All students in the class were asked five main questions on blended learning and their readiness to face IR4.0.

The paper addresses two important questions. Firstly, to what extent are students comfortable with blended learning, particularly flipped classroom, and secondly, how do they perceive blended learning as a medium to assist them in coping with IR4.0 after they graduate.

Before further discussion, it is pertinent to provide an overview of the paper. The paper begins with this introduction, followed by selected literature that discusses key concepts to be used in this paper. The third section

Manuscript received July 3, 2019; revised September 13, 2019.

J. Juhary is with the Language Centre, National Defense University of Malaysia, Kuala Lumpur, Malaysia (e-mail: jowati@upnm.edu.my). describes the methodology of this paper, and the fourth section presents the data collected. The last section offers recommendations for further action and closes the discussion of this paper.

\section{Selected Literature}

\section{A. IR4.0}

IR4.0 can be simply understood as industrial revolution in manufacturing and industry. IR4.0 places emphasis on transformative actions on automation, data exchanges, cloud, cyber-physical systems, robots, Big Data, artificial intelligence, Internet of Things and semi-autonomous industrial techniques to realize smart industry and manufacturing goals, combining human intelligence, new technologies and innovation [1]. Accordingly, as the community faces a technological revolution, the way people communicate and work changes, and it will be a vast adjustment that humankind has yet to experience.

\section{B. Blended Learning}

Various definitions emerge to suit different contexts of blended learning. One of them is by defining it in terms of its strength and weakness on a continuum [2]. This suggests that blended learning is understood by analyzing how it functions in various situations; on one hand, it can be an advantageous platform in one situation, on the other, it could also be a disaster in another situation with differing variables. Garrison and Vaughan [3] claimed that blended learning is suitable for educators, who want to promote a student-centered, self-paced, flexible and multi-modal approach to learning. Uploading learning materials online does not constitute blended learning. Given that, the author opines that blended learning is a teaching and learning approach that integrates online and face-to-face teaching and learning. There are various positive effects of using blended learning, such as engagement of students during classroom sessions is increased, and they become more active participants of learning [4].

Horn and Staker [5] proposed four models of blended learning, including rotation model, flex model, a la carte model and enriched virtual model (see Figure 1). The author focuses on the first model, rotation model, for her classroom teaching and learning since it is the most appropriate for her environment. There are four sub strategies under rotation model, including station rotation model, lab rotation model, flipped classroom model and individual rotation model. Each model functions well in different environments. Particularly relevant for this paper is flipped classroom, where the next sub section explains this model in brief. 


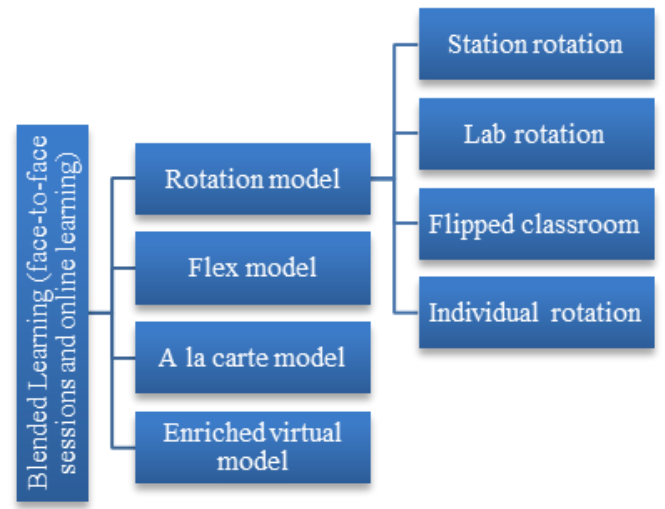

Fig. 1. An adapted blended Learning model [6].

\section{Flipped Classroom}

Flipped classroom is argued to becoming a well received concept due to the demands of education to utilize digital technology for teaching and learning. Flipped classroom permits educators to upload their teaching videos, lecture notes or reading materials online, and students will have to access these before coming to classes [7]. In so doing, students will have more opportunities to understand the materials that they have accessed, and as such, more active and interactive dialogues will happen in the classroom.

The practice in flipped classroom is students must access online materials relevant to the week before coming to the classes. This means that the students will come prepared to debate/discuss/argue about the lessons of the day during classroom sessions. Now, students do their homework with the help of the educators during face-to-face sessions. In Malaysia, success stories on flipped classroom are evident in some higher learning institutions, including Universiti Sains Malaysia, Penang and Universiti Kebangsaan Malaysia, Selangor.

\section{Methodology}

The methodology adopted was a mixed method approach; an observation and a set of checklist were used to observe the same group of students for two semesters, and a survey was distributed online at http://bit.ly/2XwnJhc for them to answer at the end of the second semester. The students are second year students during the 2018/2019 Academic Session, and they are the students of the National Defense University of Malaysia (NDUM). The same students were taught by the author for two semesters (two different courses) The author applies blended learning through the flipped classroom strategy during both semesters. The students were periodically observed, and asked about how they think of the activities during classroom learning. The author did not conduct any lectures during the two semesters; only activities, including games were conducted to support online materials uploaded on the University's Learning Management System (LMS) (see Fig. 2 and 3 for screenshots of the online materials).

At the end of the second semester, all students in the class were invited to participate in an online survey, consisting of five main questions on blended learning and their readiness to face IR4.0. The items asked were adopted from previous research on flipped classroom and blended learning [8], [9]. The answers were computed using Statistical Package for the Social Sciences (SPSS) Version 25. Descriptive and inferential analysis was also done using SPSS.

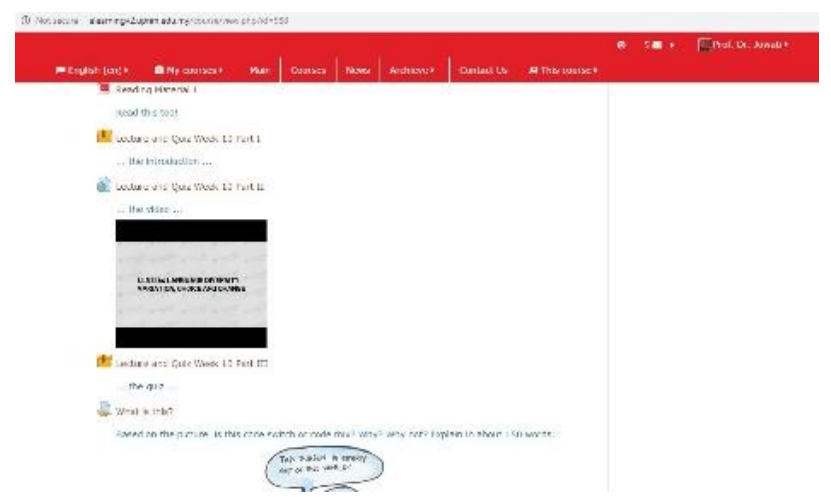

Fig. 2. A screenshot of the LMS for LLS3364 (first semester course, the 2018/2019 academic session).

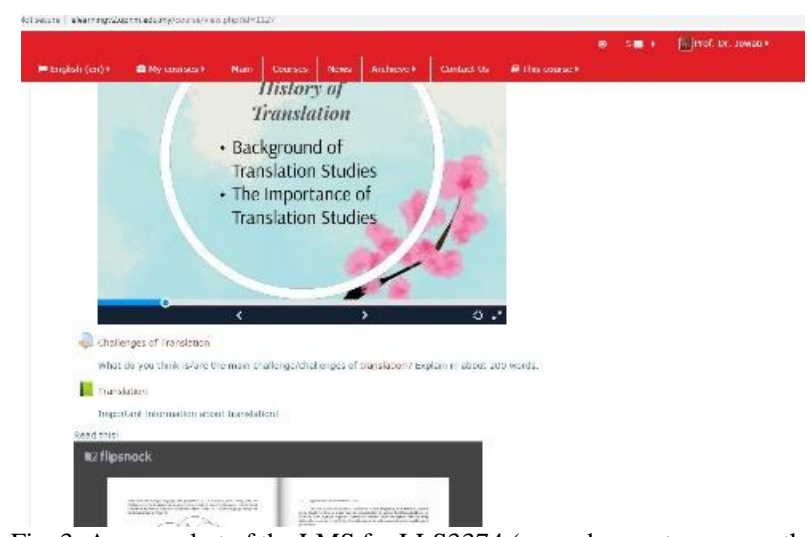

Fig. 3. A screenshot of the LMS for LLS3374 (second semester course, the 2018/2019 academic session).

\section{ANALYSIS AND DisCUSSIONS}

\section{A. Demographic Information}

This section begins with demographic information about the respondents. There are 59 students in total for both courses in two semesters: 49 female and 10 male students (Figure 4). All of them are students of one academic program, Bachelor of Social Sciences (Languages and Cross Cultural Communication). Figure 5 illustrates the academic achievement of the respondents based on their Cumulative Grade Point Average (CGPA). It can be concluded that the majority of the respondents (51\% or 30 students) had a CGPA between 3.00 and 3.49.

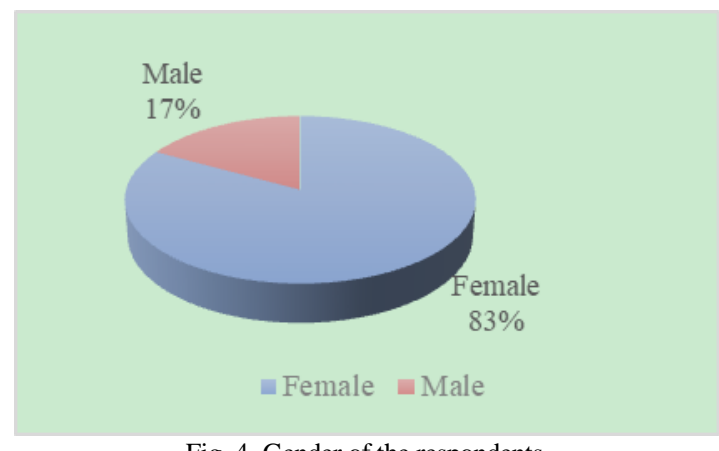

Fig. 4. Gender of the respondents. 


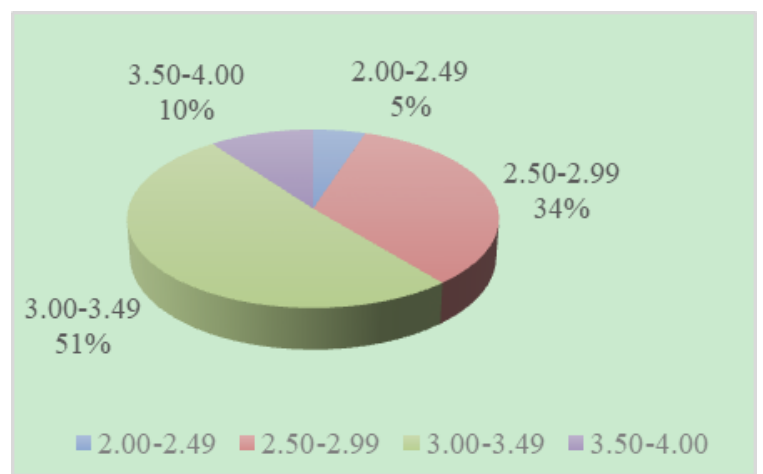

Fig. 5. CGPA of the respondents.

It can be discerned from Fig. 5 above that respondents had various academic achievement backgrounds. This suggests that what they shared in terms of their preferences for blended learning, and how IR4.0 could help them may provide answers to the issues addressed in this paper; given this demographic information, it does not necessarily mean that only good students can benefit from blended learning, or vice versa.

\section{B. Research Question 1 - To What Extent Are Students Comfortable with Blended Learning, Particularly Flipped Classroom}

For this research question, three main questions were asked to all respondents. The first two questions have a five point likert scale ranging from Poor, Fair, Satisfactory, Very Good and Excellent. Below are two figures to illustrate the findings of the two main questions. Figure 6 illustrates the findings for the question whether the respondents were comfortable using blended learning, especially flipped classroom, and Fig. 7 presents respondents' perceptions on whether blended learning has improved their knowledge at the beginning and end of both courses.

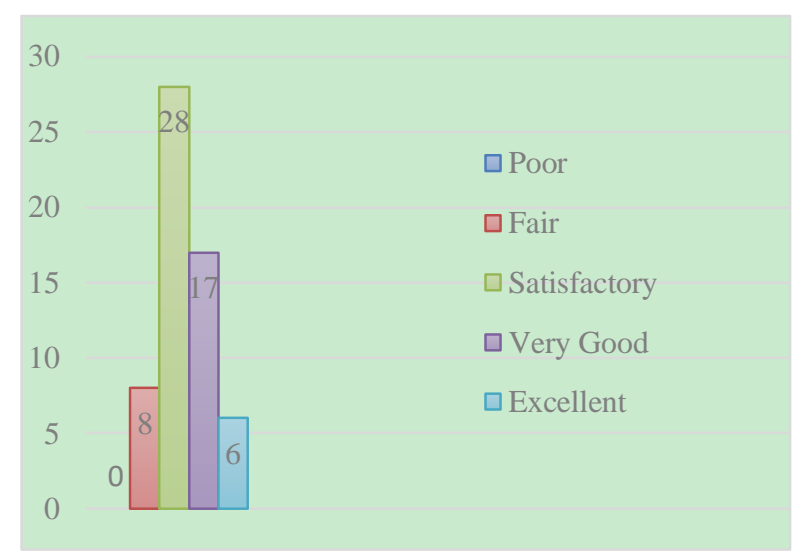

Fig. 6. Comfortable using blended learning especially flipped classroom.

Based on Fig. 6 and 7, it is argued that the respondents had reservation about whether they were comfortable using blended learning. 28 respondents (47\%) were satisfied with blended learning, especially flipped classroom. As this is the highest percentage, the author argues for two things. First, the respondents may not be comfortable with just activities during class sessions without lectures. Coming from a long tradition of rote learning since their secondary schools [10] [11], perhaps becoming independent learners poses a challenge to the students. Or possibly the second argument is that the online materials are not helping the respondents during class sessions. This is on the author, who may have failed to provide suitable materials and activities to enhance students' learning during the face-to-face sessions. Despite having another 23 respondents who chose Very Good and Excellent for their comfort level of using blended learning, eight respondents had a fair experience of using it. Again, the second reason maybe the trigger for these responses, and the author would have to improve on this matter immediately.

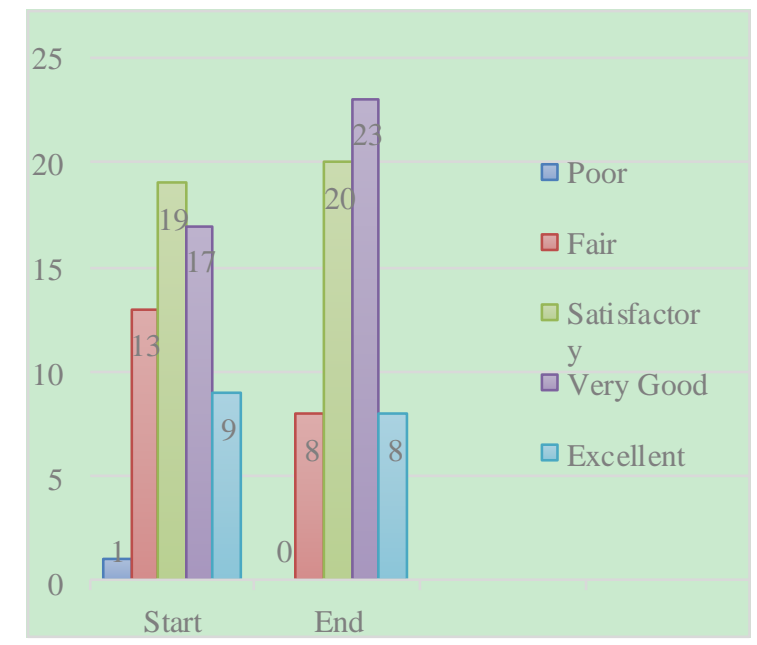

Fig. 7. Blended learning at the start and end of the courses.

Fig. 7 compares respondents' opinions about using blended learning at the start of courses and at the end of them. In general, most respondents opined that blended learning has improved their knowledge. For example, the number of respondent, who chose blended learning has fairly improved their knowledge was reduced from 13 to eight, showing that as they underwent two courses with blended learning, it has gradually improved their knowledge. Nonetheless, respondents, who chose blended learning has improved their knowledge excellently were reduced at the end of the courses, compared to at the beginning (see at the beginning nine chose Excellent and at the end of the course, only eight chose Excellent). It is perplexing to see this; alas, the author has yet to investigate this in another research.

The third main question uses a four point likert scale, including Strongly Disagree, Disagree, Agree and Strongly Agree. There are six sub items asked, and the findings are presented in Table I. It can be summarized that the respondents had a positive perceptions of flipped classroom in general since the means of four items are above 3.00 (they mostly chose Agree to these items). The standard deviations too reveal that the data points are rather spread out over a large range of values (between .508 and 1.023).

Further analysis is done on four items to check correlation between each two of them. Table II presents a positive high correlation between increased understanding when using flipped classroom and the respondents' level of engagement. This suggests that the higher the understanding of the students, the higher their level of engagement using blended learning, particularly, flipped classroom. The author argues that this is expected since the students will be more engaged 
to learn when they are able to understand critical concepts of the courses.

TABLE I: OPINIONS ABOUT FLIPPED CLASSROOM

\begin{tabular}{|c|c|c|}
\hline Items & Mean & $\begin{array}{l}\text { Standard } \\
\text { Deviation }\end{array}$ \\
\hline $\begin{array}{l}\text { The activities during Flipped Classroom } \\
\text { sessions increased my understanding of the } \\
\text { courses' critical concepts. }\end{array}$ & 3.19 & .508 \\
\hline $\begin{array}{l}\text { The Flipped Classroom session inspired me to } \\
\text { pursue further learning for the courses. }\end{array}$ & 3.05 & .570 \\
\hline $\begin{array}{l}\text { My level of engagement for these courses } \\
\text { increased when they are done through Flipped } \\
\text { Classroom. }\end{array}$ & 3.15 & .582 \\
\hline $\begin{array}{l}\text { I am more motivated to learn in Flipped } \\
\text { Classroom. }\end{array}$ & 3.07 & .666 \\
\hline $\begin{array}{l}\text { With Flipped Classroom, I feel coming to } \\
\text { class is less important since I can cover the } \\
\text { class on my own using the online materials } \\
\text { given. }\end{array}$ & 2.49 & 1.023 \\
\hline $\begin{array}{l}\text { Flipped Classroom helped me to study the } \\
\text { courses independently. }\end{array}$ & 2.85 & .784 \\
\hline
\end{tabular}

TABLE II: CORRELATION BETWEEN INCREASED UNDERSTANDING AND LEVEL OF ENGAGEMENT

\begin{tabular}{|c|c|c|c|}
\hline & & $\begin{array}{c}\text { FC } \\
\text { Increased }\end{array}$ & $\begin{array}{c}\text { FC } \\
\text { Engagement }\end{array}$ \\
\hline \multirow{3}{*}{ FC Increased } & Pearson & 1 & $.661 * *$ \\
\hline & Sig. (2-tailed) & & .000 \\
\hline & $\mathrm{N}$ & 59 & 59 \\
\hline \multirow{4}{*}{$\begin{array}{l}\text { FC } \\
\text { Engagement }\end{array}$} & Pearson & $.661^{* *}$ & 1 \\
\hline & Correlation & & \\
\hline & Sig. (2-tailed) & .000 & \\
\hline & $\mathrm{N}$ & 59 & 59 \\
\hline
\end{tabular}

Similarly, Table III reports the same trend where a positive high correlation is evident. As flipped classroom inspires the respondents to further their learning, they were automatically more motivated to learn in flipped classroom. The author further argues that this scenario is inevitable since students, who are interested in something will be kept motivated to continue with what they like.

TABLE III: CORRELATION BETWEEN TO PURSUE FURTHER LEARNING AND MOTIVATION TO LEARN

\begin{tabular}{|c|c|c|c|}
\hline & & FC Pursue & $\begin{array}{l}\mathrm{FC} \\
\text { Motivated }\end{array}$ \\
\hline \multirow{4}{*}{ FC Pursue } & Pearson & 1 & $.763 * *$ \\
\hline & Correlation & & \\
\hline & Sig. (2-tailed) & & .000 \\
\hline & $\mathrm{N}$ & 59 & 59 \\
\hline \multirow{4}{*}{ FC Motivated } & Pearson & $.763 * *$ & 1 \\
\hline & Correlation & & \\
\hline & Sig. (2-tailed) & .000 & \\
\hline & $\mathrm{N}$ & 59 & 59 \\
\hline
\end{tabular}

\section{Research Question 2-How Do They Perceive Blended Learning as a Medium to Assist Them in Coping with IR4.0 after They Graduate}

Two main questions are used to answer this research question. Both only use a three point likert scale of Yes, No and Not Sure. As IR4.0 is still at its infancy at the Defense University, the author opines that perhaps the best scale for the questions is Yes, No and Not Sure. Nevertheless, the respondents were required to provide reasons for their options, which will be presented in the next few paragraphs.

For the first question on whether the respondents were aware of IR4.0, 27 respondents (46\%) were aware of what IR4.0 is; 10 (17\%) had no idea of it; and $22(37 \%)$ were not sure of what IR4.0 is. Details of their reasons are presented in Table IV according to themes. The second question received only two answers from the respondents; 38 respondents (64\%) agreed that blended learning would help them face IR4.0 after graduation, and 21 respondents $(36 \%)$ opted for Not Sure. Their various reasons are categorized and tabulated in Table V.

Based on Table IV, the majority of respondents commented that they had never heard of IR4.0 or had limited exposure about it. These are exemplified by the number of respondents, who admitted that they had never heard of the term IR4.0 or may have had a limited exposure about IR4.0 (17 respondents and nine respondents, respectively). Meanwhile, 14 of them claimed that they had a minimal knowledge of IR4.0 since their lecturers talked about it during class sessions. Some of the respondents too were invited to seminars and talks on IR4.0; nonetheless, they mostly agreed that they were not well versed in IR4.0.

\begin{tabular}{lcc}
\multicolumn{3}{c}{ TABLE IV: AWARENESS OF IR4.0 } \\
\hline \hline Categories/Themes & $\begin{array}{c}\text { Number of } \\
\text { respondents }\end{array}$ & $\%$ \\
\hline Lack of exposure & 9 & 15 \\
Never heard of IR4.0 & 17 & 29 \\
A minimal knowledge on IR4.0 & 14 & 24 \\
Importance of technology for the future & 4 & 7 \\
Need to change & 5 & 8 \\
[Not relevant to the question] & 10 & 17 \\
Total & 59 & 100 \\
\hline \hline
\end{tabular}

When asked about whether blended learning could help them to face IR4.0 after graduation, 16 respondents agreed that blended learning has assisted in updating new skills and knowledge. At the same time, 12 respondents opined that blended learning leads them to becoming adaptive of a new environment. Meanwhile, six respondents claimed that blended learning allows them to be independent learners, and another five respondents agreed that blended learning could help them become thinkers that are more critical. All these positive perceptions suggest that the respondents were open about how blended learning could assist them to face IR4.0, despite their lack of or zero knowledge about the revolution.

TABLE V: BLENDED LEARNING HELPS TO FACE IR4.0

\begin{tabular}{lcc}
\hline Categories/Themes & $\begin{array}{c}\text { Number of } \\
\text { respondents }\end{array}$ & $\%$ \\
\hline Never heard of IR4.0 & 10 & 17 \\
Becoming independent learners & 6 & 10 \\
Update skills and knowledge & 16 & 28 \\
Becoming adaptive of a new environment & 12 & 20 \\
Becoming critical thinkers & 5 & 8 \\
[Not relevant to the question] & 10 & 17 \\
Total & 59 & 100 \\
\hline \hline
\end{tabular}

\section{Further Analysis and Discussions}

Based on the author's observation for two semesters, it can 
be deduced that not all respondents were comfortable with flipped classroom. For example, the author notes that should the students fail to read/watch/listen to the online materials, they were not able to participate actively during class sessions. When asked, the respondents replied that they did not have enough time to access the materials before coming to the sessions of the day. Further, some of them complained that the Internet access was problematic. Perhaps, these two were the main reasons why 36 respondents chose Fair and Satisfactory when asked whether they were comfortable using blended learning (see Fig. 6).

Despite these mishaps, the author argues that the students were considerably active during class sessions. The author uses various activities, including games to enhance students' understanding of the online materials (see Fig. 8). For example, the author prepares crossword puzzles for revision sessions. At times, students were asked to do mind maps of critical concepts, draw them on the board and present them to the whole class. The author would then provide comments and feedback on the mind maps. All students were encouraged to ask questions on the lessons of the day. Again, this can be supported by the data in Fig. 7 and Tables I, II and III.

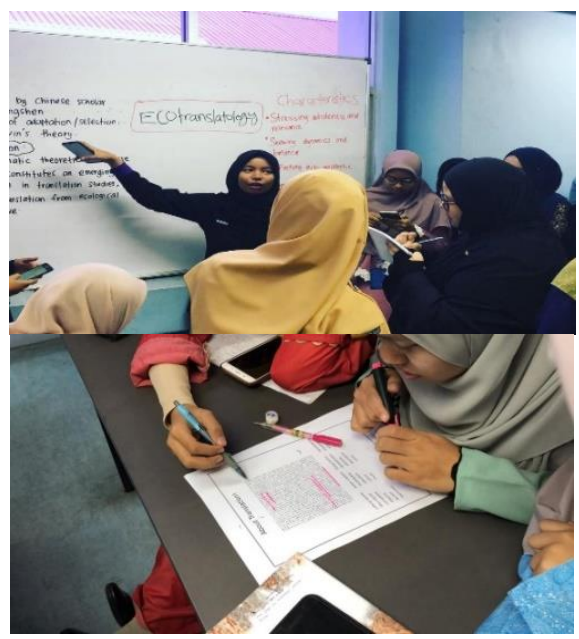

Fig. 8. Activities to support blended learning

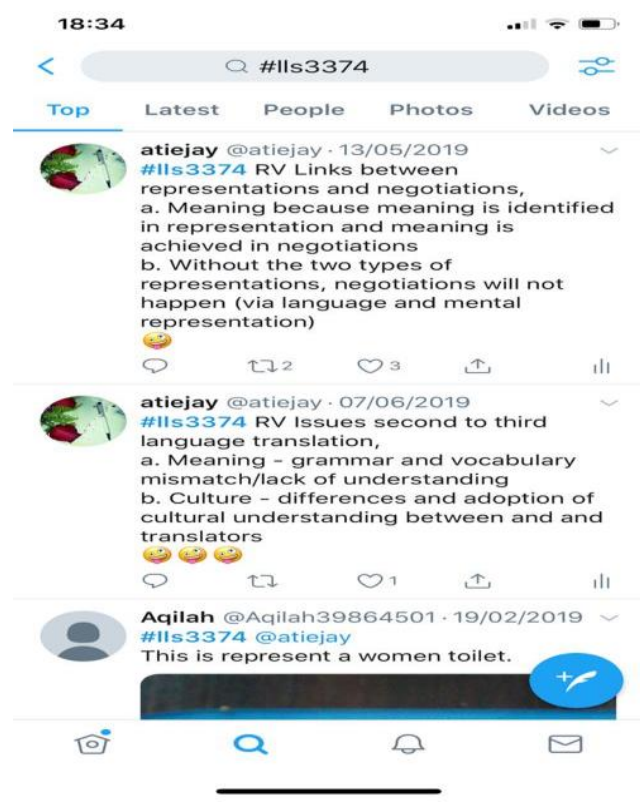

Fig. 9. Revision on Twitter for LLS3374.
The author further supports the students' learning by providing tweets on Twitter for revision purposes (see Figure 9). Based on the author's observations, students took advantage of technology and the precise feature of messages on Twitter to do last minute revision for tests and examination. It can be argued that since students learn differently, each one of them may require different learning tools to study. Blended learning, particularly flipped classroom, does enrich students' learning experience by allowing them to be critical thinkers and independent learners.

\section{RECOMMENDATIONS AND CONCLUSIONS}

Given the analysis and discussions in the previous section, two issues must be solved in order to ensure students are provided with the right and rich learning environment. Firstly, students should be given exposure to the current happenings of the world. This can be done by organizing seminars and workshops, where speakers in relevant industries are invited. At the same time, the curriculum of the University must be tailored toward preparing the future graduates for IR4.0. Integration of relevant skills, such as critical and analytical thinking, must be strengthened in the current syllabi.

Secondly, in preparing the students to face IR4.0, the academics too must be given proper training in delivering the curriculum, or pedagogy. They must be comfortable too to embrace changes, and to be adaptive of the changing needs of the industry. Chalk and talk may still be relevant in some scenarios; however, as students have different expectations of their learning environment, perhaps blended learning is the way forward!

To conclude, the author is confident that with proper planning and support from the management of the University, blended learning may be used widely and effectively to assist future graduates in facing IR4.0 and beyond. Therefore, both students and academics must be ready for changes. As technology is dynamic, the need to equip students with relevant skills becomes greater. Perhaps, these graduates may face Industrial Revolution 5.0, instead of IR4.0.

\section{CONFLICT OF INTEREST}

The author declares no conflict of interest.

\section{AUTHOR CONTRIBUTIONS}

The author is the only researcher involved in conducting the research, from writing the literature review and adopting the items for the online survey, to observing the respondents during face-to-face sessions and writing the analysis and discussions for this paper. The author confirms and approves this final version.

\section{ACKNOWLEDGMENT}

The author wishes to express her gratitude to all respondents of this brief research. Further, special thank you goes to the NDUM for to opportunities to conduct this 
research.

\section{REFERENCES}

[1] Industry 4.0: The Fourth Industrial Revolution - Guide to Industrie 4.0. (2016). [Online]. Available https://www.i-scoop.eu/industry-4-0/

[2] A. Littlejohn and C. Pegler, Preparing for Blended e-Learning, Abingdon, Oxon: Taylor \& Francis, 2007.

[3] R. Garrison and H. Vaughan, Blended Learning in Higher Education: Framework, Principles and Guidelines, New York: John Wiley \& Sons, 2008.

[4] R. Alebaikan and S. Troudi, "Blended learning in Saudi universities: Challenges and perspectives," ALT-J Research in Learning Technology, vol. 18, no. 1, pp. 49-59, 2010.

[5] B. Horn and H. Staker, Blended: Using Disruptive Innovation to Improve Schools, San Francisco: Jossey-Bass, 2014.

[6] B. Horn and H. Staker, Blended: Using Disruptive Innovation to Improve Schools, San Francisco: Jossey-Bass, 2014.

[7] B. Tucker, "The flipped classroom: Online instruction at home frees class time for learning," Education Next, Winter, pp. 82-83, 2012.

[8] S. Bates and R. Galloway, "The inverted classroom in a large enrolment introductory physics course: A case study," A Report by the Higher Education Academy, 2012.

[9] Best Practices for Flipping Classroom. (2014). [Online]. Available http://www.hanoverresearch.com/insights/best-practices-for-the-flipped-c lassroom/?i=k-12-education

[10] T. P. Li, "Towards a culturally sensitive and deeper understanding of "rote learning" and memorization of adult learners," Journal of Studies in International Education, vol. 15, no. 2, pp. 124-145, 2011.

[11] S. M. Thang, "Investigating the problem of memorization among Malaysian English as second language (ESL) learners," Journal e-Bangi, 2003.
Copyright $\odot 2019$ by the authors. This is an open access article distributed under the Creative Commons Attribution License which permits unrestricted use, distribution, and reproduction in any medium, provided the original work is properly cited (CC BY 4.0).

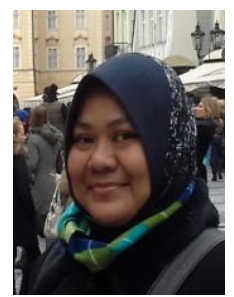

J. Juhary is a member (M) of IACSIT. She was born in Rembau, Negeri Sembilan, Malaysia about four decades ago. She received her first and second degrees from Universiti Kebangsaan Malaysia, Malaysia in teaching English as a second language and English language studies, respectively. Her PhD is on governance and development from Monash University, Australia. Juhary's areas of expertise include military pedagogy, higher education and educational technology.

She served as the director of the Language Center at the Defense University for seven years, prior to holding her current administrative position now as the Director of UPNM Press, the University's publication wing. Concurrently, she is also teaching undergraduate students, and supervising postgraduate students. She also publishes journal articles and chapters in books, including "IR4.0 Ready and Aware Academics at the National Defense University of Malaysia" in Redesigning Higher Education Initiatives for Industry 4.0 (2019) and "The Role of Military Pedagogy in Creating Internationalized Leaders of Character: The Malaysian Way" in Professional Military Education: A Cross-Cultural Survey (2019). Her research interests include military pedagogy, higher education and educational technology, focusing on language studies.

Prof. Dr. Juhary is a senior member of IACSIT since 2008. She is also a member of IET. At the national level, she was a committee member for preparing Malaysia's e-Learning Policy, and 2u2i Policy (a policy for allowing 2-year study at the university, and 1-year training at the industry for undergraduate students). 